\title{
Switched Reluctance Generator - Modeling, Design, Simulation, Analysis and Control A Comprehensive Review
}

\author{
D.Susitra \\ Research Scholar, Department of \\ Electrical and Electronics Engineering, \\ Sathyabama University, Chennai, India
}

\author{
E.Annie Elisabeth Jebaseeli \\ Research Scholar, Department of \\ Electrical and Electronics Engineering, \\ Sathyabama University, Chennai, India
}

\author{
S.Paramasivam \\ Member, IEEE, R\&D Head, ESAB Group, \\ India
}

\begin{abstract}
Wind power as one of a greatly developed distributed generation techniques is gaining increasing significance throughout the world. Switched Reluctance Motor when operated as Generator is proved to be a real alternative to conventional variable speed drives in many applications, especially in the extraction of maximum energy in wind energy generation system with the variable wind speeds. This paper reviews the technology status and recent trends of switched reluctance generator covering the various aspects of Modeling, Design, Simulation, Analysis and Control.
\end{abstract}

\section{Keywords}

Switched Reluctance generator, Variable speed drives, wind power Generation

\section{INTRODUCTION}

Switched reluctance Motor (SRM) have been found to offer important advantages over conventional AC machines in generating as well as motoring operations and has proved to be the potential candidate for many industrial applications. The researches on this machine had been focused on the motoring operation over a long period of time. Since the machine has the good reversibility characteristics and the SRG can run as good as SRM, fewer scholars took notice on the generating mode of SRM. This led to the increased interest in researchers of electrical community as this machine is an attractive solution for worldwide increasing demand of electrical energy. The shortcomings of the conventionally used generators have turned research attention to a more simple and robust variable speed switched reluctance generator (SRG) which exhibits the most desirable features of a generator [1-12].

The published literature on switched reluctance generators has dealt with the technical issues related to the machine technology such as generator modeling, design, simulation, analysis and control. In this paper an attempt has been made to provide comprehensive review of publications in this regard.

This paper has been organized as follows. Section II discusses in detail the design issues and various application developments of SRG. Various aspects of modeling and simulation of SRG drive system are discussed in section III. Section IV reviews the diverse analysis aspects of SRG. A review of conventional and intelligent controllers applicable to SRG drive system is the topic of interest in section V. The application potential and futuristic trends are briefly presented along with conclusive remarks in section VI.

\section{History, Design and Application Developments of Switched Reluctance Generator}

The switched reluctance machine as a motor has been known for over 150 years. The generating mode of this machine SRG has created considerable interest during past few years in machine systems which either generate or regenerate. Although it is one of the earliest discovered machines, special power requirements limited the earlier investigation and application. Development of power electronic components and the advent of cheap microcomputers renewed the research interest in SRG.

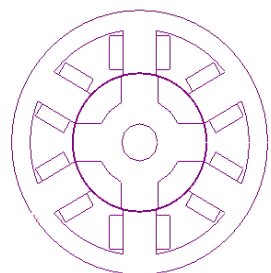

Fig. 1 Cross section of the Switched Reluctance Machine

The inherent simple construction, ruggedness, wide speed range of operation, low cost, fault tolerant capability, easy cooling simple excitation, requirement of simple converter circuit, high torque volume ratio, high efficiency and suitability under harsh environments are some of the important advantageous features of switched reluctance machine. The simple construction of the doubly salient, singly excited switched reluctance machine is shown in fig. 1.

\section{A. Excitation Methods}

The recent research shows that the SRG is inherently completely passive and has no self excitation capability. To overcome this problem some researchers used a slot of permanent magnet on the edge of the stator pole to create a magnetic field that run through the 
rotor to both sides of the stator; the rotation of the rotor will change the permanent magnetic flux which induces alternating voltage in the stator winding. The others have chosen an external power source to help in self excitation for this SRG like using a battery or capacitor to create a magnetic field around the stator winding for a set time and then this magnetic field will be used to create electricity when the rotor moves [1].

The concept of attaching rectangular pieces to each pole of the machine phase for self excitation has been presented and implemented the same in three different means in [13]. The Permanent magnet material used is Samarium Cobalt. In the first option of magnet placement, the stator core was cut around the teeth of one phase from top surface towards bottom of the core. Several lamination layers of each tooth were removed and room for the permanent magnets was provided. The second option that has been implemented comprises only permanent magnets fastened to the stator poles without cutting the stator core. The last option for a self excited SR Generator design was the same as the first case except that only two instead of four permanent magnet pieces were fastened on each phase tooth on only one side of the stator core.

\section{B. Design Concepts}

The SRG system is made up of the SRG, the power converter and the controller. There are different structures of SR Generators such as 12/8 structure, 6/8 structure, 6/4 structure, 6/10 structure, 6/12 structure, $8 / 6$ structure and so on. The electromagnetic design and the design procedure for the 3 phase 12/8 structure SRG is presented in [14].It is shown that the design method and the procedure presented are general for all types of SRG systems irrespective of the structure of the generator and based on the design method and procedure ,a software package for electromagnetic design of the SRG had been developed. A design study of 3 phase SRG to investigate the influence of stator and rotor poles on the machine performance at low speed for use in direct drive wind energy converter is presented in [15] and from the results it is shown that if the machine is not driven into saturation ,the low pole numbered machine perform as good as high pole numbered machine and the machine with the more rotor poles than stator poles had shown good performance.

A $50 \mathrm{KW}$ SR Generator system which includes the SRG, the asymmetric exciting commutation power converter and the microprocessor controller is developed in [16] and the equations for electric loading, the rated average electromagnetic torque and the rated average electromagnetic power are given. Paper [17] has contributed the design procedure and formulae for the multi-pole single phase SRG and the same has developed a CAD \& simulation program for a $2 \mathrm{KW} / 750 \mathrm{rpm} 8$-pole prototype SRG. This technique is based on the quasi linearity model and overcomes the drawbacks of the analogy method which is commonly used in the design of SRM. Magnetic design plays a central role in the design of SRG. The main objectives in the design of super- high- speed generators such as a) reliable $\&$ fast built up of voltage, b) high efficiency performance, c)

Fault tolerance in operation d) structural integrity at super high speeds and e) high frequency effects are discussed in [18].

The design (magnetic and Thermal designs)and fabrication of a SRM drive for a flywheel as a part of a wind/diesel stand-alone generator in order to minimize the number of start-stop cycles of the diesel engine are discussed in [19] and the illustrations for both magnetic and thermal models from the same are shown in figs. $2 \& 3$. Magnetic design basically aims to define from some initial constraints such as size and geometry of the machine to achieve the required values of torque at a given speed. For a machine with the linear magnetic system, the torque( $\mathrm{T}$ ) for a constant current (I) can be derived as from the self-inductance variation of the active poles $\mathrm{L}(\theta)$ with the rotor position $\theta$ as :

where

$$
T(\theta)=\left(\frac{1}{2}\right)\left(\frac{\partial L(\theta)}{\partial \theta}\right) * I^{2}
$$

$$
\begin{aligned}
& \mathrm{L}-\text { self inductance } \\
& \theta \text { - rotor position }
\end{aligned}
$$

A simple model to evaluate $\mathrm{L}(\theta)$ can be deduced with the help of fig.2.a.

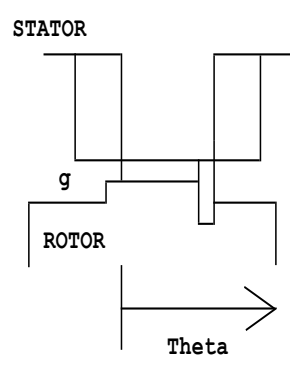

Fig.2.a

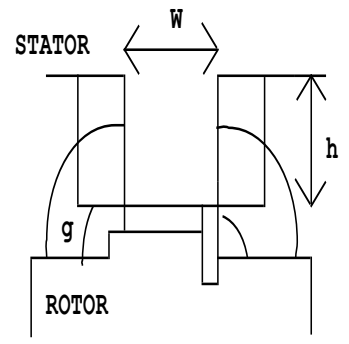

Fig2.b
Fig.2.a - Flux Model Only central flux Fig.2.b - Lateral flux included

A simplified model with the electrical equivalent circuit

(heat sources replaced by current sources and thermal resistances by electrical resistances) for the thermal analysis of SR machine is shown in fig. 3 .

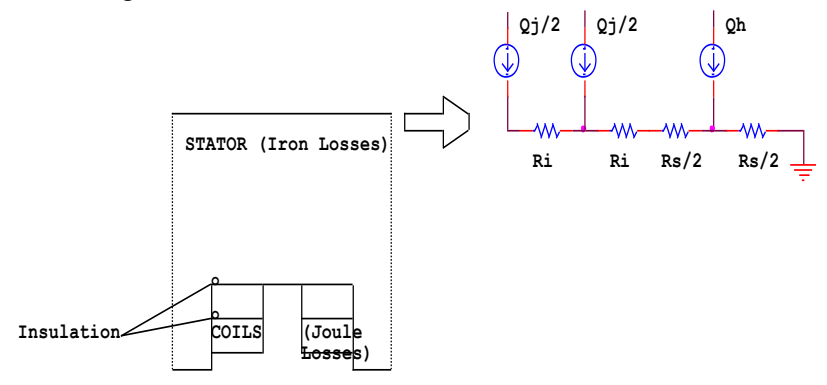

Fig.3.Thermal model for temperature computation

The principles and the procedure for the design of the SRG system based on the software package based on non-linear models are presented for a three-phase 12/8 structure SRG system in [20]. For a two channel Switched Reluctance starter/generator system ,a new design concept was developed in [21] by placing the pole windings for a set of common pole pairs in parallel instead of placing them in series thereby increasing the number of turns per pole. This is desirable to reduce the size of the wire used for the windings which in turn reduces the eddy current losses in the conductor windings. The comparison of the three-phase 12/8 structure SR machine and the four-phase 16/12 structure SR machine was made at the same operational conditions and the same volume in the respects of the 
basic output frequency and output capacity of the machine and is presented in [22].The work in [23] has presented the conception of an SR Machine flywheel system considering many design aspects such as material choice, mathematical modeling and control strategy. An investigation and five different design analysis of a $300 \mathrm{KW} \mathrm{SRG} \mathrm{is}$ presented in [24]. Different designs of the machine are evaluated to provide $300 \mathrm{KW}$ at $30,000 \mathrm{rpm}, 60,000 \mathrm{rpm}$ and $100,000 \mathrm{rpm}$ and $100 \mathrm{KW}$ at $100,000 \mathrm{rpm}$. The different designs are compared in terms of size, weight, efficiency and torque.

\section{Application Developments}

From the later 1980s, United States began to develop the switched reluctance starter/generator which used to startup the engine and then act as the high voltage DC supply for their avions. In [35] an AC selfexcited SRG has been analysed as a battery charger. In [24], best design methodologies for the application of SRG as an auxiliary power unit in a light weight, high speed and high power military and other types of hybrid vehicles are presented. A SRG that can be used in an air cycle machine is designed and presented in [6]. Authors of $[23,48]$ have presented a flywheel energy storage system employing SRG. In [10] two kinds of mechanical coupling of the SRG with the wind turbine (direct coupling with the turbine shaft and coupling to the shaft through a gear box)are analysed. In [45] the researcher has developed a $75 \mathrm{KW}$ switched reluctance variable speed wind generator system prototype and the experimental test results for two control strategies are shown and compared. In [49,50], a $2.5 \mathrm{KW}$ experimental prototype has been constructed and the performance of the wind energy conversion system has been tested over the whole speed range using wind profile and power impacts and the experimental results are also presented. In [51], the configuration of a small size wind power generating system and a maximum power point tracking control method is proposed. In [52] the dynamic response of an SRG based wind turbine system during normal wind variation and system fault condition has been examined..In [54] a 20 KW prototype machine has been developed and tested. In [58], an 8/8 configuration of a single-phase SRG applied for wind power generation is discussed. All these research papers [10], [45], [49-52], [54] and [58] have explored the suitability of SRG for wind energy applications.

\section{Modeling and Simulation of Switched Reluctance Generator}

Many modeling techniques have been proposed and developed for Switched Reluctance Motor(SRM) which are the basis for the modeling of SRG. Various modeling methods are

1)Linear method

2) Non linear method

3)Mathematical method

In a linear model in which the magnetic curve is simplified as straight line and inductance can be calculated analytically and the accuracy of this model is low. In Piecewise linear model the magnetization curve is approximated as a two segment straight line which slightly improves the accuracy. Analytical equation is used to build the SRM model, still the required accuracy is not achieved. Neural Network model has a structural complexity. Feed forward artificial neural network is employed in SRM modeling with simultaneous excitation of two phases.

In [25] the pi-sigma Neural network model which is the combination of neural network and fuzzy logic is employed to develop the non linear model which can be applied to torque control and current control. Paper [26] presents a new approach for developing an equivalent circuit of SRG.A full mathematical model with 7 equations has been developed. Simulation model \& experimental set up of 3-phase 6/4 SRG controlled by hysterisis control has been established. A numerical model of SRG is dealt in [27] for use on SPICE. The electric and magnetic circuits are coupled by proper controlled sources and the method is useful for circuit analysis, design optimization and calculation of dynamic behavior of SRG. The model can be easily applied to the simulation of wind turbine generation system considering the output characteristics of wind mill. Another Simulation model in simulink has been developed in [28] which is used to analyze the working zones that the generator experiments within a cycle. A mathematical model is derived from a set of four equations which completely describes the dynamic behavior of the 6/4 SRG and is given in $[29,30]$ as below.

SRG phase voltage can be expressed as follows:

$$
V=R i+\frac{d \lambda}{d t}
$$

where $\lambda$ is generator phase flux linkage which is a function of both phase current and rotor position, Therefore equation 2 can be rewritten as

$$
V=R i+\left(\frac{\partial \lambda}{\partial t}\right)\left(\frac{d i}{d t}\right)+\left(\frac{\partial \lambda}{\partial \theta}\right)\left(\frac{d \theta}{d t}\right)
$$

For a given current $\mathrm{L}$ is a function of rotor position and is a linear quantity. Hence equation 3 can be rewritten as

$$
V=R i+L\left(\frac{d i}{d t}\right)+i \omega(\partial L / \partial \theta)
$$

Where

$$
e=i \omega(\partial L / \partial \theta)
$$

The voltage equation of SRG is given by equations (4) \& (5). The electromagnetic and mechanical torque are given by equations (6) \& (7) respectively.

$$
\begin{gathered}
C_{\text {emag }}=1 / 2\left(\frac{i_{a}^{2} \partial L_{a}}{\partial \theta}+\frac{i_{b}^{2} \partial L_{b}}{\partial \theta}+\frac{i_{c}^{2} \partial L_{c}}{\partial \theta}\right) \\
C_{m}=-C_{\text {mag }}+\frac{J d \omega}{d t}+D \omega
\end{gathered}
$$

where ia, ib, ic ,La, Lb, Lc are currents and inductances of the three phases respectively and $\omega=$ angular speed $; \mathrm{J}=$ moment of inertia; $\mathrm{D}=$ frictional coefficient.

A mathematical model for SRG is derived from the equations (4) - (7) and is as shown in equations (8) \& (9). 


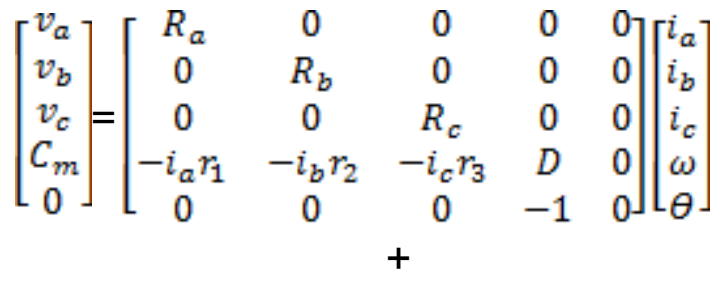

$$
\left[\begin{array}{ccccc}
L_{a} & 0 & 0 & 0 & i_{a}\left(\frac{\partial L a}{d \theta}\right) \\
0 & L_{b} & 0 & 0 & i_{b}\left(\frac{\partial L b}{d \theta}\right) \\
0 & 0 & L_{c} & 0 & i_{a}\left(\frac{\partial L c}{d \theta}\right) \\
0 & 0 & 0 & J & 0 \\
0 & 0 & 0 & 0 & 1
\end{array}\right]\left[\begin{array}{c}
i_{a} \\
i_{b} \\
i_{c} \\
\dot{\omega} \\
\dot{\theta}
\end{array}\right]
$$

$$
\begin{aligned}
& \text { Where } \quad r_{1}=1 / 2\left(\frac{\partial L_{a}}{\partial \theta}\right) \text {; } \\
& r_{2}=1 / 2\left(\frac{\partial L_{b}}{\partial \theta}\right) ; \\
& r_{3}=1 / 2\left(\frac{\partial L_{c}}{\partial \theta}\right)
\end{aligned}
$$

In [31] ,the power inverter, excitation source and loads were modeled based on simulink / Sim Power Systems (PSB) and this proposed model is used to analyze the affections of different load status and work environments to the dynamic \& static performances of SRG system. A detailed system model for a More Electric aircraft power system equipped with a SRG is described in [32]. Both the linear \& non-linear mathematical models of SRG were established in [33], the linear model for the simulation of phase current and energy conversion process and the non-linear model to analyze the characteristics of SRG operation in self-excitation and separately excitation mode.

A single phase SR AC Generator has been simulated (simulink) and analyzed in steady state in [34].It is shown in their work that the machine returns mechanical energy to the prime mover twice per cycle and it can be both supplying and returning electrical energy at the same time. In [35], an Ac self-excited SRG used is analyzed using a second order nonlinear oscillator model which can be used as a battery charger in isolated locations. The modeling of a linear SRG is dealt in [36]. The mathematical modeling of the main circuit of the exciting power converter during the period of excitation and the period of generation is dealt [37].

\section{Analysis of Switched Reluctance Generator}

In [38], a study is made on the smoothening of torque profile of Switched reluctance motor by 2-D finite element approach, Pole geometric modifications and stator pole shoe introduction. An analysis of SRG feeding an isolated load is presented in [39]. In this the generator performance has been investigated by a software development kit based on object oriented program technique.

An analysis of the SRG's faults and excitation requirements is essential to utilize the fault tolerance capability of this machine in aerospace starter / generator and in various automotive applications. One such research has been undertaken in [40] to identify, analyze and simulate various fault modes of SRG and investigation about SRG's excitation requirements with and without faults has been carried out. Another study on fault -tolerant operation of multipole single-phase 8/8 structure of SRG has been carried out in [41, 42] where open and short-circuit coils are studied through linear analysis, finite element analysis and static torque measurement. In [43] the quality analysis of SRG based on piece-wise approximation has been presented. In this two SRG constructions, one with strong magnetic saturation is compared with the one with the linear characteristics and it is shown that the former has larger power output than the later. In [44], the complete analysis, modeling and simulation with the drive circuit has been presented for different types of loads.

\section{Controllers for Switched Reluctance Generator}

There are four control issues of SRG such as

1) angle position control ;

2) chopping-current control ;

3) PWM control ; and

4) direct extinction voltage control .

These main control variables are due to the threshold of the exciting current indirectly. Excitation process can be controlled through regulating turn-on and turn-off angles. At low and medium speed operation the SRG phase current is regulated using PWM control of magnetizing voltage and for high speeds it is controlled using a single pulse mode. Constant power output control with the constant output voltage of SRG is implemented in [45] with the following control strategies.

1) fixed conducting angle PWM control strategy

2) variable conducting angle control strategy

The structure of SRG controller for speed -control and powercontrol applications and the details for commutation of SRG are discussed in [46]. In [47, 48] the topology and control methods of SRG drive are compared with the topology \& control of conventional AC drives and the control of SRG for flywheel energy storage system for the application in UPS is discussed.

A closed loop control of power output of SRG to drive a wind energy conversion system to the point of maximum aerodynamic efficiency is presented in $[49,50]$. A maximum power point tracking control and constant resistance control methods for SRG are proposed in [51]. A control system for the grid side inverter is presented in [52] and a control technique of a SR starter/generator system has been patented in [53].

There are two voltage control schemes namely voltage feedback control and commutation shift control scheme. In lower driving speed and heavier load conditions, the voltage feedback regulation control ability under chopping switching mode will be failed and under such circumstances dynamic commutation shift controller is suggested in [54 -56] and tested on an experimental prototype model of SRG in [54].

The range of design parameters and control variables that generate maximum output power are investigated in [57]. The speed feedback control method for the SRG system described in [58] is illustrated in fig. 4 to make the wind turbine work at an optimal speed. The variable speed control has the potential to increase the energy capture. 


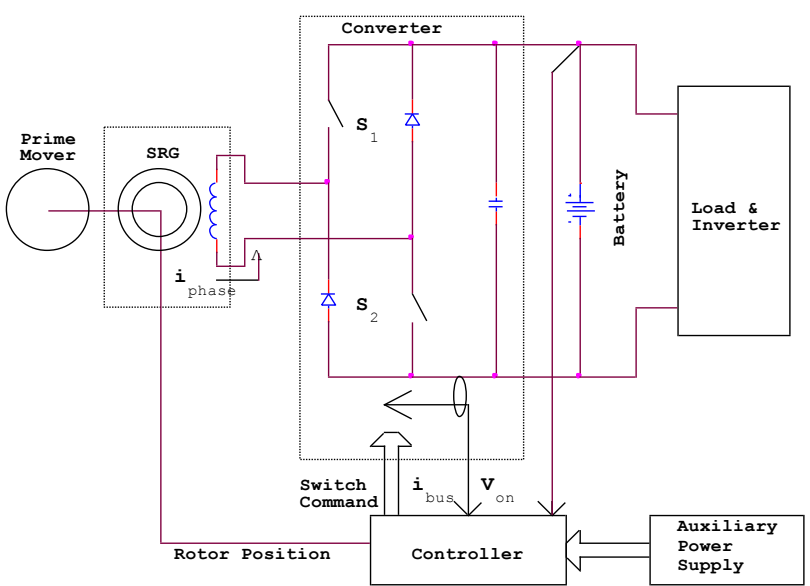

Fig. 4 Hardware Implementation of the system

A closed loop control of DC-bus voltage with only phase currents as control parameters (current control through soft chopping with PI plus PWM technique) with the fixed turn-on and turn-off angles for a four-phase SRG is presented in [59] and the real time control was implemented in digital signal processor environment.

SRG control based on torque ripple minimization is presented in [60] in which an asymmetrical torque sharing function is investigated and compared with the trapezoidal one. Since the voltage control of SRG by closed-loop control is difficult because of the severe nonlinear magnetic characteristics, another method of voltage control by employing a fuzzy logic controller (FLC) in SRG system is suggested and the procedure for designing the FLC is presented in [61] and the FLC control scheme was implemented with the microprocessor. A closed loop power control algorithm that automatically maintains the most efficient excitation angles in producing the required amount of electric power is implemented and demonstrated in simulation in [62].

One of the major criteria for optimization of the SRG performance is the efficiency. With optimal excitation angles (turn-on and conduction angles) maximization of efficiency by minimizing the losses was carried out in [63]. A problem of optimal efficiency in single pulse controlled SRG drive operating on a wide speed range is investigated in [64-66] and a controller that online determines the optimal turn-on and turn-off angles is proposed for providing high efficiency and low torque ripple and a smooth transition between PWM control mode to single pulse control mode is achieved in [66].

A new Sparse PWM converter is investigated in [67, 68] which is shown to overcome the problem of voltage instability under openloop control in an asymmetric converter. Also the new Sparse converter eliminates the requirement of two stages power conversion, reduces the switch count and eliminates the front-end current smoothing inductor thereby reducing the cost and the size of the converter. A new switching strategy to increase the overall productivity of the SRG is introduced in [69] by using a intermediate freewheeling mode during the control process. A new commutation approach has been developed in [70] that has demonstrated a increase in output current at low bus voltages. It is also shown analytically that the ripple current at the output of the inverter is reduced resulting in a lower bus voltage ripple for a given output filter.

\section{CONCLUSION}

This paper has presented a comprehensive technology review of switched reluctance generators. The characteristics of SRG which includes simplicity of control, robustness, wide speed ranges and reliability makes it a potential candidate for many industrial applications especially for the power generation in harsh environments such as wind energy conversion systems. Therefore it is reasonable to foresee that in the medium power wind systems the SRG allow good performance in extracting the maximum energy carried by the wind with the increased transformed ratio of wind energy / electrical energy and reduced cost of wind generating electricity. Recent researches are involved in the development of intelligent controllers to utilize the maximum potential of switched reluctance generator for wider applications. Various technical aspects of modeling, design, analysis and control in switched reluctance generators have been reviewed comprehensively.

\section{REFERENCES}

[1] M.Nassereddine, J.Rizk, and M.Nagrial, Switched reluctance generator for wind power applications. In Proc. World academy of science, Engineering and Technology, vol. 31, pp. 126-130, July 2008.

[2] Eleonora Darie, Costin Cepisca and Immanuel Darie. The use of switched reluctance generator in wind energy applications. In Proceedings of EPE-PEMC, 2008, pp. 1963-1966.

[3] Chen Wang, Liming Wang, Libao Shi and Yixin Ni. A survey on wind power technologies in power systems. Power Engineering Soceity General Meeting,June 2007, pp. 1-6.

[4] H.Li and Z.Chen Overview of different wind generator systems and their comparisons. in Proc.IET Renewable Power generation. 2008,Vol. 2, No.2, pp. 123-138.

[5] Arthur V.radun. Switched reluctance generator for generating AC power. U.S.Patent 5,381,081, Jan.10, 1995.

[6] Eakman et al. Switched reluctance generator. U.S.Patent 5,726,560, Mar. 10, 1998.

[7] Nikolay Radimov, Nattan ben-hail and Raul Rabinovici. Switched reluctance machines as three phase $\mathrm{AC}$ autonomous generator. IEEE Trans. Magnetics, Vol. 42, no.11, pp. 3760-3763 Nov. 2006.

[8] B.Bekkouche, A.Chaouch and Y.Mezari.A. Switched reluctance motor analysis using permeance network method. Applied Engineering Research., Vol. 1, pp. 137-152, 2006.

[9] Nikolay Radimov, Nattan ben-hail and Raul Rabinovici. Switched reluctance machines as three phase AC autonomous generator. IEEE Trans. Magnetics, pp. 1697-1701, 2003.

[10] Pedro Lobato and A.J.Pires(2004, Sep 8).The switched reluctance generator for

Wind

Power conversion.[online].Available:http://www.aedie.org/9chlie.

[11] Chen Hao and Song Qiushuang. A Switched reluctance variable speed generator. In Proceedings of CCECE, 2003, pp. 467470.

[12] Liu Chuang, Yan Jiageng, Zhu Xuezhong and Liu Diji Investigation and practice for basic theory of switched reluctance generators. In Proceedings of International Conference on Electrical Machines and Systems, Sep.2005, pp. 575-579.

[13] Velimir nedic and Thomas A.lipo, "Experimental verification of induced voltage self-excitation of a switched reluctance generator,"

Industry Applications $\quad$ Conference, 2000 pp.51-56. 
[14] H.Chen, "Electromagnetic design of switched reluctance generator," in Proc. Fifth international conference on power Electronics and drive systems, 2003, pp. 777-780.

[15] M.A.Mueller. Design of low speed switched reluctance machines for wind energy converters. in Proc. Nineth International Conference on electrical Machines and Drive, No.468, IEE 1999 pp. 60-64.

[16] H.Chen, F.Xiao, D.Su, Y.Zhu and F.Wang. A 50 KW switched reluctance generator System. In Proceedings of International conference on Power system technology,2002, pp. 1173-1177.

[17] Su shaoping and Li Qingfu. Design of multi-pole single phase switched reluctance generator.In Proceedings of International conference on Electrical machines and systems, Aug 2001, pp. 938941.

[18] Chris S.Edrington, B.Fahimi and Ray B.Sepe. Sensorless superhigh speed switched reluctance generators. In Proceedings of IEEE, 28th Annual Conference on Industrial Electronics Society, Nov 2002, pp. 1026-1031.

[19] I.J.Iglesias, L.Garcia-Tabares, M.Lafoz, J.Calero, S.Portillo, I.Cruz, F.Toral and B.Abramian.A fly wheel switched reluctance motor drive For wind energy application.

[20] H.Chen and L.Ji, "Design of switched reluctance generator system based on the software package for windows. In Proceedings of the 6th International Conference on Advances in Power System Control, Operation and Management, Nov 2003, pp. 384-388.

[21] A.V.Radun, C.A.ferreira and E.Richard. Two channel switched reluctance starter/generator results. In Proceedings of Applied Power Electronics Conference and Exposition, APEC, Feb 1997, pp. 546-552.

[22] Chen Hao and Lu shengli.Comparison of three-phase 12/8 structure switched reluctance machine and four-phase 16/12 structure switched reluctance machine. In Proceedings of 4th International Conference on Power Electronics and Motion Control , Aug. 2004 , pp.1005-1008.

[23] L.G.B.Rolim, A.C.Ferreria, G.G.sotelo and R.de Andrade Jr. Flywheel generator with switched reluctance machine.[online].Available:http//www.coe.ufrj.br. U.F.R.J-Federal University of Rio de janerio, Brazil.

[24] Gabriel Gallegos-Lopez, Fred Reiter, Jr.Kaushik Rajasheaar and Ronald J.Krefta.300 KW Switched reluctance generator for hybrid vehicle applications. presented at society of Automotive Engineers ,inc, March 2002.

[25] Jie Xiu, Chang-liang Xia.Modeling of switched reluctance motor based on Pi-Sigma neural network.IEEE international symposium on Industrial electronics,June 2007 pp. 1258-1263.

[26] Martin Liptak, Valeria Hrabovcova and paolrafajdus.Equivalent circuit of switched reluctance generator based on DC series generator. Journal of Electrical Engineering, Vol 59, , pp. 23-28, No.1, 2008.

[27] Osamu Ichinokura, Tsukasa Kikuchi, Kanji Hackamore, Tadakki Watanabe and Hai-Jiao Guo."Dynamic simulation model of switched reluctance generator. IEEE trans. Magnetics, Vol. 39, No. 5, pp. 3253-3255, September 2003.

[28] Abelardo Martinez, Javier Vicuna, Francis Perez, Eduardo laloya, Bonifacio Martin, Tomas Pollan and Beatriz Sanchez and Juan Llado. Simulation model of an AC autonomous switched reluctance generator. In Proceedings of EUROCON 2007, The International Conference on Computer as a Tool, Warsaw Sep. 2007, pp. 1674-1678.

[29] Augusto Fleury, Felipe dos Santos e Silva, Sarizon Alves De Andrade and Jose Luis Domingos.A Switched reluctance generator behaviour under different conditions. In Proceedings of IEEE
International symposium on Industrial Electronics, June 2007, pp. 1282-1287.

[30] Augusto Fleury, Darizon Alves De Andrade, Felippe Dos Sandos E Silva and Jose Luis Domingos.Switched reluctance generator for complementary wind power generation in grid connection. In Proceedings of IEEE International Machines \& Drives conference,May 2007,pp.465-470.

[31] Shoujan Song and Weiguo Liu.A novel method for nonlinear modeling and dynamic simulation of a four -phase switched reluctance generator system based on MATLAB SIMULINK. In Proceedings of 2007 Second IEEE conference on Industrial Electronics and Applications, pp. 1509-1514

[32] Timothy L.Skvarenina, Oleg Wasyne Zuk and Paul C.Krause.Simulation and analysis of a switched reluctance generator/motor electric aircraft power system. In Proceedings of 31st linter society Energy Conversion Engineering Conference, Aug 1996, Vol. 1, pp. 143-147.

[33] Pan Zai-Ping, Jin Ying and Zhang Hui, Study on switched reluctance generator. Journal of Zhejing University Science2004,[online].

Available:http//www.zju.edu.cn/jzus/2004/0405/040513.

[34] Abelardo Martinez, Javier Vicuna, Francis Perez, Eduardo laloya, Bonifacio Martin, Tomas Pollan, Beatriz Sanchez and Juan Llado.Steady state behaviour of an AC autonomous switched reluctance generator. in Proc.European Conference on Power Electronics And Applicaion,Sept 2007, pp.1-8.

[35] Abelardo Martinez et al.Use of an AC Self-excited switched reluctance generator as a battery charger. In Proceedings of 13th International Power Electronics and Motion Control Conference, 2008, pp. 845-849.

[36] H.Polinder, V.C.Mecrow, A.G.jack, P.Dickinson and M.A.Mueller.Linear generators for direct drive wave energy conversion. In Proceedings of International Conference on Electrical Machines \& Drives,June 2003,pp. 798-804.

[37] Chen Hao, Su Tao, Xiao Fang and Zhu Yifeng.A switched reluctance wind generator with the excitation of low voltage. In Proceedings of IEEE International Conference on System Man and Cybernetics, Vol 6, Oct 2002.

[38]K.N.Srinivas and R.Arumugam. Analysis and improvement of torque profile in the switched reluctance drives. In Proceedings of 26th Annual conference of Industrial Electronics society,2000,pp. 381-386.

[39] M.K.el-Nemr, M.A.Al-Khazendar, E.M.Rashad and M.A.Hassaniin, Modeling and steady state analysis of switched reluctance generator. In Proceedings of IEEE Power Engineering Soceity, General Meeting 2003, pp. 1894-1899.

[40] Iqbal Husain, Arthur Radun and John Nairus.Fault analysis and excitation requirements for switched reluctance generators.IEEE trans. Energy Conversion, Vol.17, no.1, pp. 67-72, March 2002.

[41] Tadashi Sawata, Philip C.Kjaer, Calum Cossar and Yoichi Hayashi.Fault-tolerant operation of single - phase SR generators.IEEE trans. Industry Applications, Vol.35, No.4, pp. 774781 July/Aug 1999.

[42] Tadashi Sawata, C.Kjaer, Calum Cossar and T.J.E.Miller.A study on operation under faults with a single phase SR generator. IEEE trans Industry applications, Vol .35, No.4, pp. 782-789, July/Aug 1999.

[43] Raul Rabinovici and Nikolay Radimov. The switched reluctance generator as a flux compression electromechanical converter. In Proceedings of Conversion on Electrical and Electronics Engineers in Israel, IEEE Sep 2004, pp. 321-324. 
[44] M.Abou-Zaid, Magdy El-Attar and M.Moussa.Analysis and performance of axial field switched reluctance generato. In Proceedings of International Conference on Electrical Machine and Drives, May 1999, pp. 141-143.

[45] Hao Chen, Chao Zhang and Xucheng Zhao.Research on the switched reluctance wind generation System. In Proceedings of IEEE International Conference on Systems, Man, Cybernetics, Oct 2001, pp. 1936-1941.

[46] David A. Torrey.Switched reluctance generators and their control. IEEE trans. Industrial Electronics,Vol.49, No.1, pp. 3-13, February 2002.

[47] Elenora Darie and Emanuel Darie. The control of switched reluctance drives.[online]Available:http//snet.elth.pub.ro/snet 2004.

[48] K.De. Bravandere, J.Driesen and R.Belmans. The control of switched reluctance drives and their use for flywheelenergystorage.[online]Available:

http//www.kuleuven.be/ei/public/publications.

[49] Roberto Cardenas, Ruben Pena, Marcelo Perez, Jon Clare, Greg Asher and Patrick Wheeler.Control of a switched reluctance generator for variable-speed wind energy applications.IEEE trans. Energy Conversions, Vol.20, No.4, pp. 781-790, December 2005.

[50]Roberto Cardenas, Ruben Pena, Marcelo Perez, Greg Asher, Jon Clare, Pat Wheeler.Control system for grid generation of a switched reluctance generator driven by a variable speed wind turbine. In Proceedings of 30th Annual conference of the IEEE Industrial Electronics society, November 2-6, 2004, pp.1879-1884, Buan, Korea.

[51]K.Ogawa, N.Yamamura and M.Ishda. Study for Small size wind power generating system using switched reluctance generator. In Proceedings of IEEE International Conference on Industrial Technology, Dec 2006, pp. 1510-1515.

[52] D.McSwiggan, L.Xu and T.Little. Modeling and control of a variable-speed switched reluctance generator. In Proceedings of UPEC 2007, pp. 459-463.

[53] Heglund et al.Switched reluctance starter/generator system and method of controlling same. U.S.Patent 6,011,377,Jan. 4, 2000.

[54] Lyon, and France.Design and performance of a $20 \mathrm{KW}, 100 \mathrm{rpm}$ switched reluctance generator for a direct drive wind energy converter. In Proceedings of IEEE international conference on electrical machines and drives, May 2005, pp. 56-63

[55] Yuan-Chih Chang and Chang-Mingliaw.Development and voltage feedback control for a switched reluctance generator. In Proceedings of International Conference on Electrical Machines And Systems, Oct 2007, pp. 392-397.

[56] Yuan-Chih Chang and Chang-Ming Lia. On the design of power circuit and control scheme for switched reluctance generator.IEEE trans. Power Electronics, Vol.23, No.1, pp. 445-454, January 2008.

[57]P.Asadi, M.Ehsani and B.Fahimi. Design and control characterisation of switched reluctance generator for maximum output power. In Proc. APEC 2006, pp. 1639-1644.

[58] Zhang Qixue, Wang Xiangheng, Zhu Xuezhong and Liu Diji.A small 1-phase switched reluctance generator for wind power generation. In Proceedings of fifth International Conference on Electrical Machines and Systems, Aug 2001, pp. 1003 -1006.
[59]P.Chancharoensook and M.F.Rahman.Control of a four-phase switched reluctance generator: experimental investigations. In Proceedings of IEEE International conference on Electrical Machines and Drives, pp. 842-848, June 2003.

[60] L.Moreau, M.Machmoum and Mezain. Control and minimization of torque ripple in switched reluctance generator. In Proceedings of European Conference on power Electronics and Application, Sep 2005.

[61] Ke Liu Manfred Stiebler.Voltage control of a switched reluctance generator by means of fuzzy logic approach. In Proceedings of sixth Electrical and Electronics Equipment, 1998, pp. 443-446.

[62] Yilmaz Sozer and David A. Torrey. Closed loop control of excitation parameters for high speed switched reluctance generators.IEEE trans. Power Electronics, Vol 19.No.2, pp. 355-362, March 2004.

[63] Jawad Faiz and Reza Fazai.Optimal excitation angle of a high speed switched reluctance generator by efficiency maximization. In Proceedings of !2th International Power Electronics And Motion Control Conference, Aug 2006, pp. 287-291.

[64] Iordanis Kioskeridis and Christos Mademlis.Optimal efficiency control of switched reluctance generators. IEEE trans. Power Electronics, Vol 21, No.4, pp. 1062-1071, July 2006.

[65] Christos Mademlis and Iordanis Kioskeridis.Optimizing performance in current-controlled switched reluctance generators.IEEE trans. Energy Conversions, Vol.20, No.3, pp. 336365, September 2005.

[66] Christos Mademlis and Iordanis Kioskeridis.Smooth transition between optimal control modes in switched reluctance motoring and generating operation. In Proceedings of IPST 2007 in Lyon, France, pp. 1-7.

[67]Nand K.Singh, John E.Fletcher, Steve J.Funny, Douglas M.Grant, and Barry W.Williams.Evaluation of sparse PWM converter for switched reluctance generator. In Proceedings of International Conference on power Electronics \& drives System,2005 ,pp. 721-725.

[68] Nand K.Singh, John E.Fletcher, Steve J.Finney, Douglas M.Grant, Barry W.Williams.A novel switched reluctance generator inverter topology for AC power generation. In Proceedings of 3rd international Conference on Power Electronics,April 2006,pp.32-35.

[69] Stuart Dixon And Babak Fahimi. Enhancement of output electric power in switched reluctance generators. In Proceedings of IEEE International Electrical Machines and Drives Conference, June 2003,Vol. 2, pp. 849-856.

[70]William S.Heglund, Stephen R.jones and Sundstrand Aerospace. Performance of a new commutation approach for switched reluctance generator. In Proceedings of Energy Conversion Engineering Conference, Vol. 1, Aug 1997, pp. 574-579. 